\title{
Lives of a Journal
}

\author{
Atwood D. Gaines • Brandy Schillace
}

Published online: 14 August 2014

(C) Springer Science+Business Media New York 2014

In July, Culture, Medicine and Psychiatry developed two new 'lives'. As with most journals, CMP began as a print only entity, distributed by means of the traditional post. Over time, the journal entered the digital age and developed a non-print life. Now the vast majority of CMP's subscriptions are digital and downloads of the Journal articles surpass 60,000 per year. With our September issue, Culture, Medicine, and Psychiatry announces other 'digital lives' of the Journal that have recently appeared online and are accompanied by a new website: culturemedicinepsychiatry.com.

Increasingly, we rely on the interconnectivity that digital platforms provide. The real-time dissemination through Twitter, Facebook, and the blogosphere are now facts of life and are the new more rapid means of communication and contact. The CMP blog and its linked social media platforms (@CMPjournal and FaceBook) will provide insights from a millennial medical anthropology that synthesizes medical anthropology and other medical social sciences, medical history, bioethics, and medical humanities. Additionally, the website facilitates easier and more direct access to submission requirements, news, and updates (and links to our issues on SpringerLink). The present issue, which features a special section, demonstrates another way CMP seeks flexibility, and offers specific guidelines for the various categories of submissions with each appearing as pages on the site.

Due to the success of the Journal over the last 7 years, we now welcome some three to four times the submissions that CMP received at the start of the tenure of the present Editor-in-Chief (mid 2007). As a consequence, CMP has been moved to streamline our double-blind peer-reviewed submission process by migrating to an online tracking system. At the same time, however, we are interested in preserving personal contact with our authors and recognize the impersonality and other problems with the vagaries of digital interaction. Thus, the Managing Editor, (Dr)

A. D. Gaines $(\bowtie) \cdot$ B. Schillace

Case Western Reserve University, Cleveland, OH, USA

e-mail: atwood.gaines@case.edu; brandy.schillace@case.edu 
Brandy Schillace, will remain the primary contact for CMP. She is reachable via email, and CMP's editorial staff will continue to guide authors through the process of submission (and resubmission).

The major changes for CMP will be its acquisition of new "lives" on the internet and in the blogosphere. This online presence will increase the Journal's availability to our audience and authors and will also provide additional essays and invited guest posts during and between published numbers of the Journal.

As we have for the last 7 years, CMP will continue to engage innovative iterations of the social sciences of medicine and the medical, medical history, narratology, and medical ethics and doubtless new aspects of each of these fields which the Journals seeks to synthesize and to present without boundaries or demarcations.

As the French say, 'plus ça change....'. So it is that we at CMP ask our readers to join us as we initiate new lives of the Journal and continue its new synthesis, all to contribute to the CMP's enduring goal of increasing the comparative and crosscultural understanding of illness and healing, patients, and healers. 